\title{
Advances in the Management of Mandibular Condylar \\ Fractures
}

Editor

MARTIN B. STEED

\section{ATLAS OF THE ORAL AND MAXILLOFACIAL SURGERY CLINICS OF NORTH AMERICA}

www.oralmaxsurgeryatlas.theclinics.com

Consulting Editor

RICHARD H. HAUG

March 2017 • Volume 25 • Number 1 